\title{
Another Possible Origin of Temperature and Pressure Gradients across Vane in the Crookes Radiometer*
}

\author{
Kazuki DENPOH ${ }^{* 1, a)}$ \\ ${ }^{*}$ Individual Participant, Kai-city, Yamanashi 400-0104, Japan \\ (Received July 12, 2017, Accepted September 15, 2017)
}

In conventional studies on the Crookes radiometer, vane temperature was presumed to be higher at the black side than at the shiny side. In this study, a new hypothesis - vane is isothermal but accommodation coefficients are different at the black side and at the shiny side - has been proposed and examined using heat transfer and Direct Simulation Monte Carlo (DSMC) simulations. The results prove that the vane is indeed isothermal under the sunlight and that gas temperature and pressure at the black side with the perfect accommodation coefficient become higher than those at the shiny side with a small accommodation coefficient. The pressure gradient across the vane acts as an area force to push the vane from the black side. It is also found the glass bulb temperature strongly affects the revolution of the vanes.

\section{Introduction}

The Crookes radiometer ${ }^{1,2}$ was invented in the 19 th century and even today still attracts many researchers as an interesting subject for study because of complicated physics involved in its simplest machinery. Therefore, significant efforts have been made via numerical simulations $^{3-10)}$ to reveal forces on vanes in the radiometer.

In those studies, the vane temperature was supposed to be much higher at the black side due to larger photon energy absorption than at the shiny side. In addition, accommodation coefficient was assumed to be the same at the both sides of the vane, and in many cases the perfect accommodation coefficient was specified. Their simulation results showed thermal transpiration (or thermal creep force) was produced due to temperature difference $\Delta T$ given between both sides of the vane and an area force by pressure difference $\Delta p$ induced across the vane. Those forces push the vanes from the black side.

However, one might wonder whether such that large temperature difference $\Delta T$ can really exist inside the thin vane. Therefore, in this study, a new hypothesis - the thin vane heated by the sunlight is isothermal but accommodation coefficients are different at the black side and at the shiny side - has been proposed and examined.

Accommodation coefficient $\alpha^{11,12)}$ is a fraction indicating how much gas molecules impinging a wall accommodate to the wall temperature $T_{\mathrm{w}}$ and described as $\alpha=\left(T_{\mathrm{i}}\right.$ $\left.-T_{\mathrm{r}}\right) /\left(T_{\mathrm{i}}-T_{\mathrm{w}}\right)$, where $T_{\mathrm{i}}$ and $T_{\mathrm{r}}$ are the temperatures of incident and reflected molecules, respectively. The reflection is perfectly specular for $\alpha=0$ and diffuse one for $\alpha=$ 1. It is well known that accommodation coefficient significantly affects gas heat conduction, especially in the transition regime to the free molecular flow regime ${ }^{12)}$.

Naturally, the accommodation coefficient at the black

* Presented as a contributed poster at the 58th annual symposium of the Vacuum Society of Japan, Aug. 18, 2017.

a) E-mail: denpoh@mvi.biglobe.ne.jp side of the vane must be larger than that at the shiny side since the mica vane in the Crookes radiometer was blackened with soot on one side ${ }^{13}$, and in experiments by Ota, et al. $^{3,4)}$ one side of aluminum (Al) vane was coated with carbon-black powder. Porous and rough ${ }^{12}$ ) surfaces of such soot or carbon-black powder could make the effective accommodation coefficient nearly unity due to frequent interactions between molecules and those surfaces.

This article is organized in the following manner. Time variations of the vane temperature are estimated through heat flux balance equations in the next section. Then, in section 3, effects of accommodation coefficients on rarefied flow fields formed around four vanes in a radiometer are investigated using a DSMC software ${ }^{14)}$, which runs on the Microsoft Excel. Finally, we give conclusions of the present study.

\section{Evaluating Vane Temperature}

Figure 1 illustrates a one-dimensional (1D) model of heat fluxes coming into and going out from a vane. The heat flux $q_{\text {in }}$ incoming from the sunlight to the vane through the glass bulb is perfectly absorbed only at the black side of the vane. And outgoing fluxes by gas heat conduction and radiation are emitted from the both sides of the vane. The perfect accommodation coefficient is as-

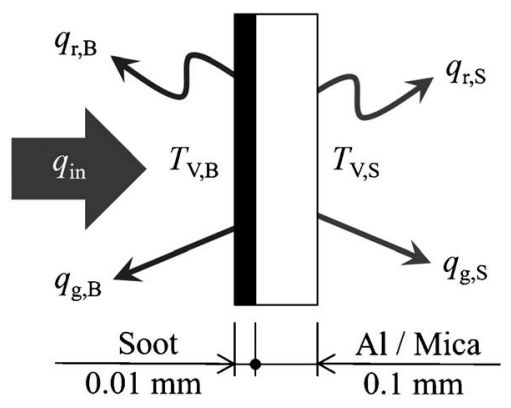

Fig. 1 1D model of heat fluxes coming into and going out from a vane. 
sumed at the both sides of the vane as most conventional studies did. Presuming the Biot number $B i$ is much less than unity $(B i \ll 1)$, heat flux balance equations to solve the vane temperature $T_{\mathrm{V}}$ at time $t$ can be simply written as lumped ones, i.e.,

$$
\begin{aligned}
& q_{\mathrm{in}}-\left(q_{\mathrm{g}, \mathrm{B}}^{t}+q_{\mathrm{r}, \mathrm{B}}^{t}\right)=-\kappa \frac{\partial T_{\mathrm{V}}^{t}}{\partial x} \\
& \rho L_{\mathrm{b}} C_{\mathrm{p}} \frac{\partial T_{\mathrm{V}}^{t+\Delta t}}{\partial t}=q_{\mathrm{in}}-\left(q_{\mathrm{g}, \mathrm{B}}^{t}+q_{\mathrm{r}, \mathrm{B}}^{t}\right)-\left(q_{\mathrm{g}, \mathrm{S}}^{t}+q_{\mathrm{r}, \mathrm{S}}^{t}\right)
\end{aligned}
$$

where, $\kappa$ is the thermal conductivity, $\rho$ the density, $L_{\mathrm{b}}$ the thickness, and $C_{\mathrm{p}}$ the specific heat at constant pressure of the vane, respectively. The superscriptions $t$ and $t+\Delta t$ indicate time, $\Delta t$ being the time step. The heat fluxes outgoing from the vane, i.e. $q_{\mathrm{g}}$ by gas heat conduction and $q_{\mathrm{r}}$ by radiation heat transfer are described as,

$$
\begin{aligned}
& q_{\mathrm{g}, \mathrm{B} / \mathrm{S}}^{t}=\frac{1}{4} n \bar{v} \Delta E=\frac{1}{2} n k \sqrt{\frac{8 k T_{\mathrm{g}}}{\pi m}}\left(T_{\mathrm{V}, \mathrm{B} / \mathrm{S}}^{t}-T_{\mathrm{g}}\right), \\
& q_{\mathrm{r}, \mathrm{B} / \mathrm{S}}^{t}=\varepsilon_{\mathrm{B} / \mathrm{S}} \sigma\left\{\left(T_{\mathrm{V}, \mathrm{B} / \mathrm{S}}^{t}\right)^{4}-T_{\mathrm{g}}^{4}\right\},
\end{aligned}
$$

where, $n$ is the gas density, $\bar{v}$ the mean thermal velocity of gas molecules, $m$ the mass of a gas molecule, $k$ the Boltzmann constant, $T_{\mathrm{g}}$ the ambient gas temperature, $\varepsilon$ the emissivity, and $\sigma$ the Stefan-Boltzmann constant, respectively. The subscriptions $\mathrm{B}$ and $\mathrm{S}$ denote the black side and the shiny side of the vane.

Figure 2 shows the vane temperature $T_{\mathrm{V}}$ at the black side and at the shiny side as a function of time, obtained by solving equations (1) and (2) alternately. In this calculation, $\mathrm{Al}$ and mica are chosen as a base material of the vane, and soot as its black side. Their thermal properties $^{15-18)}$ are tabulated in Table 1. The thickness is

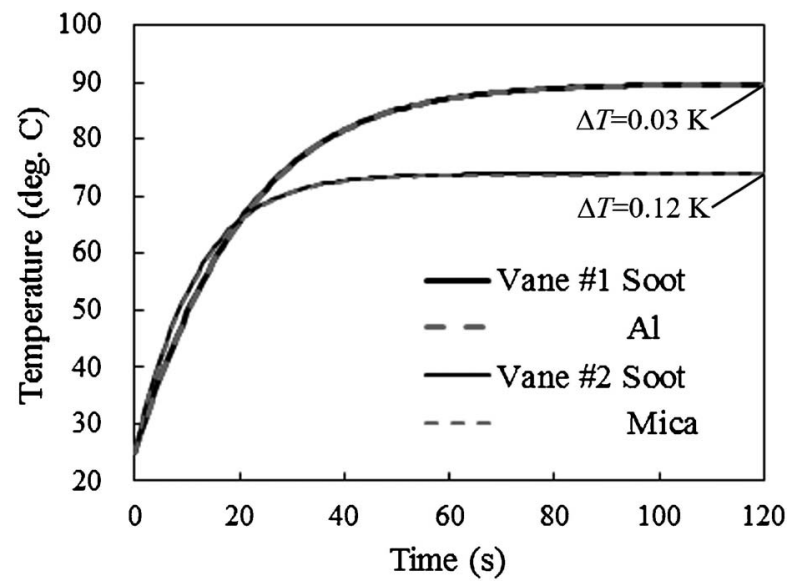

Fig. 2 Time variations of vane temperature for two different base materials, Al and mica. Each vane has a soot layer as the black side.

Table 1 Thermal properties of vane materials ${ }^{15-18)}$.

\begin{tabular}{ccccc}
\hline \hline & $\rho\left(\mathrm{kg} / \mathrm{m}^{3}\right)$ & $C_{\mathrm{p}}(\mathrm{J} / \mathrm{kg}-\mathrm{K})$ & $\kappa(\mathrm{W} / \mathrm{m}-\mathrm{K})$ & $\varepsilon$ \\
\hline Al & 2688 & 905 & 237 & 0.17 \\
Mica & 2100 & 880 & 0.5 & 0.72 \\
Soot & 100 & 1000 & 0.05 & 0.95 \\
\hline
\end{tabular}

$0.1 \mathrm{~mm}$ for the base material and $0.01 \mathrm{~mm}$ for the soot layer as shown in Fig. 1. The sunlight heat flux ${ }^{19,20)}$ is assumed to be $700 \mathrm{~W} / \mathrm{m}^{2}$, and $T_{\mathrm{g}}$ is fixed at $298 \mathrm{~K}(25 \mathrm{deg}$. C).

As plotted in Fig. 2, $T_{\mathrm{V}}$ rises with time from $T_{\mathrm{g}}$ to 363 $\mathrm{K}$ (90 deg. C) for $\mathrm{Al}$ and $347 \mathrm{~K}$ (74 deg. C) for mica, respectively. The temperature difference between the black side (soot) and the shiny side is quite small and at most $0.12 \mathrm{~K}$. The actual $B i$ calculated is less than 0.01 for each $\mathrm{Al}$ and mica vane, and therefore solving the lumped equations (1) and (2) is reasonable. Consequently, the results suggest that thin vane should be almost isothermal under the sunlight.

\section{Simulation of rarefied flows in radiometer}

Next, rarefied flows induced under the new hypothesis have been investigated using the DSMC software ${ }^{14)}$. Figure 3 depicts thermal boundary conditions of a twodimensional (2D) radiometer. The temperatures of the vane and the glass bulb are kept at $T_{\mathrm{V}}$ and $T_{\mathrm{G}}$, respectively. Each accommodation coefficient is $\alpha_{\mathrm{B}}$ at the black side and $\alpha_{\mathrm{S}}$ at the shiny side of the vane. The perfect accommodation is assumed at the glass bulb surface. The length $L_{\mathrm{a}}$ of the vane is $13 \mathrm{~mm}$. The thickness $L_{\mathrm{b}}$ is 2 $\mathrm{mm}$, which is thicker than actual one $(\sim 0.1 \mathrm{~mm})$ because of a limitation of the software. The inner radius of the glass bulb is $25 \mathrm{~mm}$.

The gas in the radiometer is air with its molecular weight of $28.97 \mathrm{~g} / \mathrm{mol}$ and two rotational degrees of freedom. The inter-molecular collision diameter is calculated from the viscosity at the reference temperature $T_{\text {ref }}$ $=\sqrt{T_{\mathrm{V}} T_{\mathrm{G}}}$. The Maxwell molecule ${ }^{21)}$ is specified as a molecular model, and collisions are treated using the variable hard sphere model ${ }^{22}$ ) and the Larsen-Borgnakke model ${ }^{23)}$. As initial conditions, the radiometer is filled with the stationary air at a reference pressure $p_{\text {ref }}$ and $T_{\text {ref }}$.

Figure 4 shows flow fields obtained for $p_{\text {ref }}=1 \mathrm{~Pa}, T_{\mathrm{V}}$ $=348 \mathrm{~K}(75 \mathrm{deg} . \mathrm{C}), T_{\mathrm{G}}=298 \mathrm{~K}\left(25 \mathrm{deg}\right.$. C), $\alpha_{\mathrm{B}}=1$ (perfect accommodation), and $\alpha_{\mathrm{S}}=0.01$. The gas temperature and thus the pressure which corresponds to the total kinetic energy of gas molecules ${ }^{24}$ become higher at the black side of the vane than at the shiny side. As a conse-

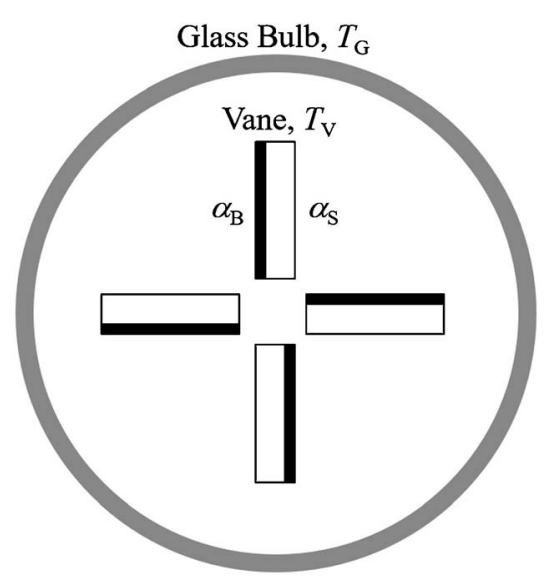

Fig. 3 Thermal boundary conditions in 2D radiometer model. 

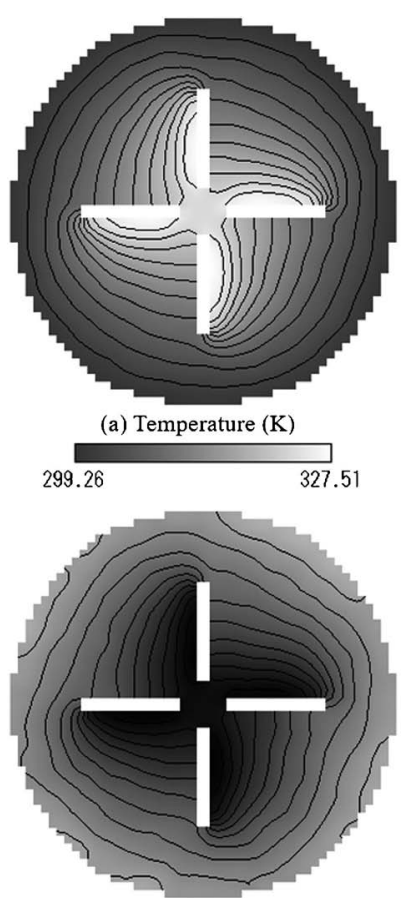

(c) Density $\left(\mathrm{m}^{-3}\right)$

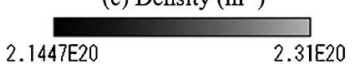

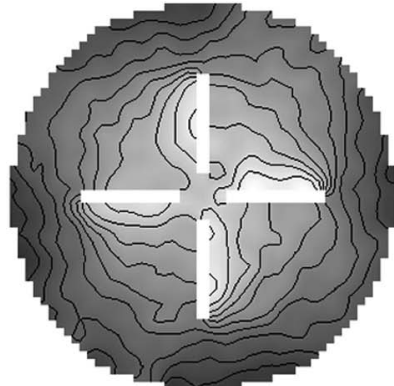

(b) Pressure $(\mathrm{Pa})$
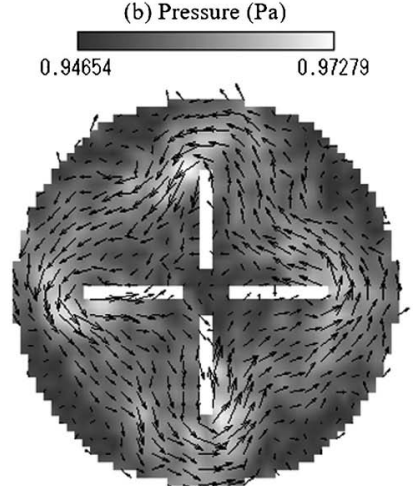

(d) Velocity $(\mathrm{m} / \mathrm{s})$

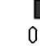

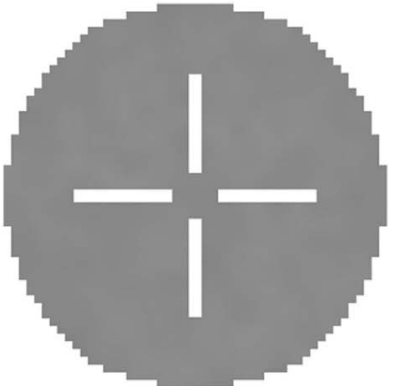
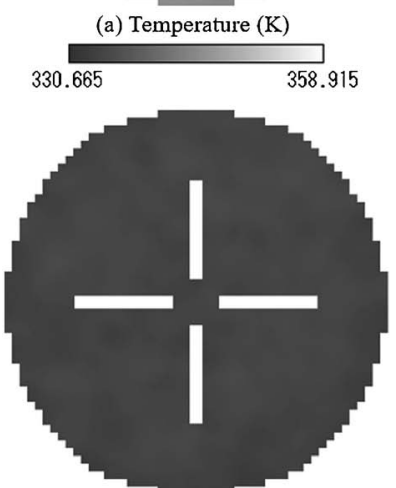

(c) Density $\left(\mathrm{m}^{-3}\right)$

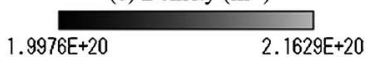

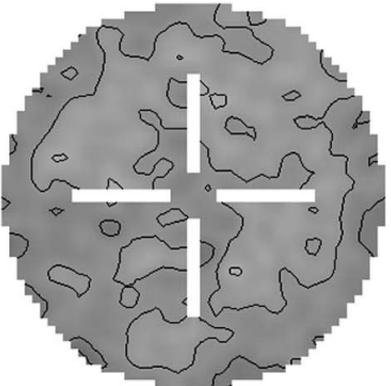

(b) Pressure $(\mathrm{Pa})$

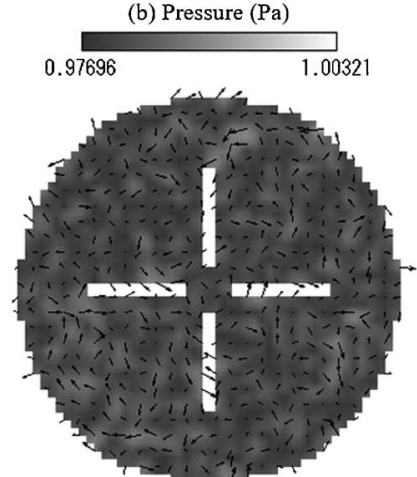

(d) Velocity $(\mathrm{m} / \mathrm{s})$

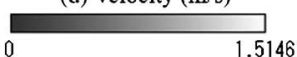

Fig. 4 Air flow fields simulated for $p_{\text {ref }}=1 \mathrm{~Pa}, T_{\mathrm{V}}=348 \mathrm{~K}, T_{\mathrm{G}}=$ $298 \mathrm{~K}, \alpha_{\mathrm{B}}=1$, and $\alpha_{\mathrm{S}}=0.01$.

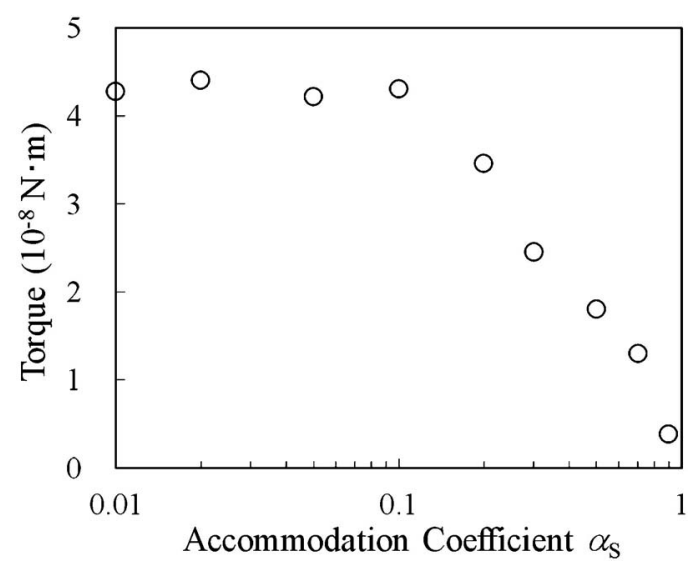

Fig. 5 Torque as a function of $\alpha_{\mathrm{S}}$, calculated for $p_{\text {ref }}=1 \mathrm{~Pa}, T_{\mathrm{V}}$ $=348 \mathrm{~K}, T_{\mathrm{G}}=298 \mathrm{~K}$, and $\alpha_{\mathrm{B}}=1$.

quence, it is proved that gas temperature and pressure gradients are produced across the vane under the new hypothesis.

Thermal creep flows are also induced around the vanes and form a large stream in the radiometer as already reported and discussed in many papers..$^{4,6-9)}$

In Fig. 5, the torque calculated from the gas pressure difference $\Delta p$ across the vanes is plotted as a function of $\alpha_{\mathrm{S}}$. The torque increases with decreasing $\alpha_{\mathrm{S}}$ for $\alpha_{\mathrm{S}}>0.1$, then becomes a constant $\left(=4.3 \times 10^{-8} \mathrm{~N} \cdot \mathrm{m}\right)$ for $\alpha_{\mathrm{S}}<$ 0.1 . The rotation speed estimated from the torque is about $4 \mathrm{rps}$ at $10 \mathrm{~s}$ after starting revolution. Although the estimation is valid only at the early state of starting rotation $^{8)}$ since the vanes are stationary in this study, the time-scale of the rotation is coincident with common ob-

Fig. 6 Air flow fields simulated for $p_{\text {ref }}=1 \mathrm{~Pa}, T_{\mathrm{V}}=348 \mathrm{~K}, T_{\mathrm{G}}=$ $348 \mathrm{~K}, \alpha_{\mathrm{B}}=1$, and $\alpha_{\mathrm{S}}=0.01$.

servations.

It is said that the revolution slows down and sometimes stops when the radiometer is exposed to the sunlight for a long time. Figure 6 shows flow fields for the glass bulb heated up to the same temperature as the vanes, i.e., $T_{\mathrm{G}}=T_{\mathrm{V}}=348 \mathrm{~K}$. Despite the large difference in accommodation coefficients $\left(\alpha_{\mathrm{B}}=1, \alpha_{\mathrm{S}}=0.01\right)$, spatial distributions of the gas temperature and the pressure are almost uniform. And any apparent thermal creep flow is not induced in the radiometer. That indicates the vanes will stop as the glass bulb is heated up to $T_{\mathrm{V}}$.

\section{Conclusion}

Unlike conventional simulation studies on the Crookes radiometer, the new hypothesis - vane is isothermal but accommodation coefficients are different at the black side and at the shiny side - has been proposed and investigated in this study. The solutions of the heat flux balance equations suggest that the thin vane should be isothermal under the sunlight. Then, the DSMC simulations proved that the contrast of the accommodation coefficients between both sides of the vane can be an origin of gas temperature and pressure gradients across the vane. The torque calculated from the pressure difference across the vanes increases as the contrast of the accommodation coefficients becomes large. Moreover, it is found that the gas temperature and the pressure gradients are also affected by the glass bulb temperature. The revolution of the vanes will stop when the glass bulb is heated up to the same temperature as the vanes. 


\section{References}

1) P. Gibbs: How does a light-mill work?, http://math.ucr.edu/ home/baez/physics/General/LightMill/light-mill.html (1996, Last accessed: 2017-05-28).

2) S. R. Wilk: The Crookes' Radiometer, Apply Light Pressure, Optics \& Photonics News (2007), p.17.

3) M. Ota, T. Nakano and M Sakamoto: Trans. Jpn. Soc. Mech. Eng. B, 65 (1999) 2016.

4) M. Ota, T. Nakano and M Sakamoto: Math. Comput. Simul., 55 (2001) 223.

5) M. Nadler: Simulation of thermal creep in light mills, http://www.moritz-nadler.de/studium/tctalk.pdf (2008, Last accessed: 2017-05-28).

6) L-H, Han, S. Wu, J. C. Condit, N. J. Kemp, T. E. Milner, M. D. Feldman and S. Chen: J. Microelectrochem. System, 20 (2011) 487.

7) S. Taguchi and K. Aoki: J. Fluid Mech., 694 (2012) 191.

8) S. Chen, K. Xu and C. Lee: Phys. Fluids, 24 (2012) 111701.

9) G. Dechristé and L. Mieussens: A Cartesian Cut Cell Method for Rarefied Flow Simulations around Moving Obstacles (2015) $<$ hal-01131756>.

10) D. Wolfe, A. Larraza and A. Garcia: Phys. Fluids, 28 (2016) 037103.

11) T. Fujimoto, S. Kato, M. Usami, T. Niimi, Y. Matsumoto, K. Nanbu, M. Nishida, T. Sawada, M. Ikegawa and M. Ota: Atomic and Molecular Flows (Kyoritsu Shuppan, Tokyo, 1996) p. 60 [in Japanese].

12) K. Denpoh: IEEE Trans. Semiconduct. Manufact., 11 (1998) 25.

13) K. Luders and R. O. Pohl: Pohl's Introduction to Physics (Springer, 2017, Switzerland) Vol. 1, p. 433.

14) K. Denpoh: DSMC_2D.xls, http://www2b.biglobe.ne.jp/ den-
poh/Software/DSMC_xls/ (2010, Last accessed: 2017-05-28) [in Japanese].

15) SENSEBEY, Thermal Properties of Materials (1), (2), (3), http://www.sensbey.co.jp/pdffile/materialpropety.pdf (Last accessed: 2017-05-28) [in Japanese].

16) K. Kuhara: Dr. Thesis, Graduate School, Guuma Univ. (2014), p. 72 [in Japanese].

17) CHINO, Table of Emissivity, http://www.chino.co.jp/ support/technique/thermometers/housyaritsu.html (Last accessed: 2017-05-28) [in Japanese].

18) HORIBA, All about Radiation Thermometer, http://www. horiba.com/fileadmin/uploads/Process-Environmental/

Documents/thermometry.pdf (2008, Last accessed: 2017-05-28) [in Japanese].

19) TECHNO, Rough Standard of Heat Flux, http://www.technooffice.com/file/heatflux-estimate.pdf (Last accessed: 2017-05-28) [in Japanese].

20) S. Maruyama: Modeling and Design of Heat Transfer, Chap. 8, http://www.ifs.tohoku.ac.jp/maru/sub/lecture/hachi2014/data/2014.10/chapter08.pdf (2014, Last accessed: 2017-05-28) [in Japanese].

21) G. A. Bird: Molecular Gas Dynamics and the Direct Simulation of Gas Flows (Clarendon Press, Oxford,1994) p. 43.

22) G. A. Bird: Molecular Gas Dynamics and the Direct Simulation of Gas Flows (Clarendon Press, Oxford,1994) p. 40.

23) G. A. Bird: Molecular Gas Dynamics and the Direct Simulation of Gas Flows (Clarendon Press, Oxford,1994) p. 104.

24) T. Fujimoto, S. Kato, M. Usami, T. Niimi, Y. Matsumoto, K. Nanbu, M. Nishida, T. Sawada, M. Ikegawa and M. Ota: Atomic and Molecular Flows (Kyoritsu Shuppan, Tokyo, 1996) p. 19 [in Japanese]. 